\title{
Functionality of lipids and lipid-protein interactions in cereal-derived food products
}

Oléagineux, Corps Gras, Lipides. Volume 10, Numéro 1, 47-56, Janvier - Février 2003, Protéines et lipides végétaux : interactions nutritionnelles et fonctionnelles

Auteur(s) : Didier MARION, Laurence DUBREIL, Jean-Paul DOULIEZ, Institut National de la Recherche Agronomique, Unité de Recherche sur les Protéines Végétales et leurs Interactions (URPVI), La Géraudière, BP 71627, 44316 Nantes cedex, France..

Author(s) : Didier MARION, Laurence DUBREIL, Jean-Paul DOULIEZ

Résumé : Les lipides et en particulier les lipides des céréales jouent un rôle important dans la transformation et la qualité des produits céréaliers de cuisson (pains, biscuits) et des boissons (bière). La plupart des mécanismes physico-chimiques responsables de la fonctionnalité des lipides a été étudiée et récemment, le rôle particulier des protéines impliquées dans la fixation des lipides, les protéines de transfert de lipides et les puroindolines a été mis en évidence. L'état des recherches menées dans ce domaine est présenté dans cette revue et les informations acquises aujourd'hui montrent que de nouvelles perspectives sont envisageables pour la sélection et la transformation en vue d'améliorer la qualité des céréales et des produits céréaliers.

Summary : Lipids and especially cereal lipids play a significant role in the processing and quality of cereals and baked cereal foods (bread, biscuits) and beverages (beer). Most of the physico-chemical mechanisms responsible for the lipid functionality has been investigated and recently the specific role of lipid-binding proteins, e.g. lipid transfer proteins and puroindolines, has been highlighted. The state of the researches performed in this field are briefly presented in this review and the data obtained until now show that new perspectives are opened in cereal breeding and processing for improving the quality of cereals and cereal products.

Mots-clés : Céréales, lipides, panification, blé, orge, brasserie, puroindolines, protéines de transfert de lipides, interactions lipide-protéine.

Keywords : Cereals, lipids, breadmaking, wheat, barley, browing, puroindolines, lipid transfer proteins, lipid-protein interaction.

\section{ARTICLE}

Introduction

In cereal derived food products, lipids are present as ingredients (fat and oils in biscuits, cakes), additives (surfactants such as lecithins, monoglycerides, sucroesters) and endogeneous components of cereals. These hydrophobic or amphiphilic molecules contribute either positively or negatively to the texture and flavour of cereal foods (bread, biscuits, cakes) and beverage (beer). Although cereal lipids account for only $1-2 \%$ of the dry flour, their impact on the processing and quality of cereal 
derived products is quite significant. In the past decades major progress has been made on the physicochemical mechanisms that are responsible for their role and functionality in cereal processing as well as on the texture and flavour of cereal products. Most of the mechanisms which have been highlighted provides useful information to optimise the use of lipid ingredients and additives in the formulation of cereal products. They also provide interesting perspectives in breeding for improving the quality of cereals. In this review we present our knowledge on cereal lipids and their physicochemical properties in strengthening on recent data on lipid-protein interactions with an emphasis on the structure and function of cereal lipid binding proteins.

\section{Cereal lipids: composition, distribution and organisation}

As in other living organisms, cereal lipids display a large structural diversity. Using classical fractionation procedures on silica based matrices, cereal lipids are separated in non polar lipids and polar lipids. Non polar lipids are mainly composed by glycerides (triglycerides, diglycerides and monoglycerides), free fatty acids, sterols and lipophilic pigments (carotenoids, tocopherol,...) while the polar lipid fraction is composed by phospholipids and glycolipids. It is obvious that, on a structural standpoint, mono- and diglycerides as well as free fatty acids display an amphiphilic character (presence of both hydrophobic and hydrophilic groups) that confer them the capability of adsorbing at air and/or oil water interfaces (see below). The non polar lipids are concentrated in the aleurone and embryo while the starchy endosperm is mainly composed by polar lipids [1] (figure 1). Therefore, in wheat technology, the milling process has a considerable impact on the lipid composition and content of wheat flour. Especially, higher yield in milling process is obviously going to increase the non polar lipid content of wheat flour.

Cereal phospholipids display a quite unique composition with the presence of high proportion of $\mathrm{N}$ acylphosphatidylethanolamine derivatives [1]. Such lipids are generally present in low amounts in both plant and animal tissues. Furthermore, the lipids tightly bound within the starch granule are mainly composed of monoacylated phospholipids, especially lysophosphatidylcholine and free fatty acids as the major component [1] (figure 1). These intrinsic starch lipids determine the physicochemical properties of starch and will not be further discussed in this review. Glycolipids are mainly composed by mono- and digalactosylacylglycerides. These galactolipids are mainly provided by the amyloplast membrane while phospholipids are the main lipid components of the cell membranes (plasmalemma), oleosome surface (natural oil droplets formed in the aleurone and embryo and covered by a phospholipid-protein monolayer) and membranes of other organelles (protein bodies, vacuoles...). Therefore, the milling process has not only an impact on the non polar/polar lipids ratio but also on the phospholipid/glycolipid ratio of wheat flour.

Here, it is also important to mention another lipid source of most cereal kernels that form the cuticular hydrophobic layers, i.e. cutin and waxes. This hydrophobic layer is generally not taken into account by most studies having a technological background while it display unique physico-chemical properties. Cutin is an hydrophobic polymer composed mainly by hydroxy fatty acid derivatives forming a tridimensional polyester network in which waxes, esters of long chain fatty acids and alcohols (> C20), are embedded [2]. These lipids and lipid structures are still widely ignored although 
they play a significant role in the diffusion of water in plant organs and in the cohesiveness of plant tissues. In cereals seeds, cutin layers could determine the adhesion between aleurone, embryo and starchy endosperm where they are located [3] as it was observed in other plants and plant organs [45]. They also form the cuticle layer covering the pericarp (bran) [3] (figure 1). Since wheat kernels are partially re-hydrated before milling in order to decrease the interactions between bran endosperm and embryo, the cutin layers, in controlling water diffusion, should be also essential to control the interactions between kernel compartments. Therefore, we could expect important consequences of these hydrophobic layers for the milling properties and consequently on the overall composition and quality of wheat flours.

Finally, it is quite important to note that the lipid composition and contents highly depend on all genetic and agro-environmental factors that influence the cell size in wheat seeds (cell membranes), the storage of lipids (oleosomes), the accumulation of protein (protein bodies and vacuoles) and starch (amyloplast) on development. Since hydrolytic enzymes are present in cereal seeds (lipase, phospholipases) some hydrolysis occur on storage of wheat grain and wheat flour leading to an increase of free fatty acids that is known to be deleterious for the quality of wheat flour [6]. Therefore, a high number of genes are directly (lipid biosynthesis) or indirectly (protein and starch synthesis) on the high diversity and variability of lipids both in term of structure and content. This means that it is illusive, in a first attempt, to control the lipid composition and content of cereals by a classical genetic approach.

Wheat lipids: from the kernel to baked products

Water-dependent reorganisation of lipid and lipoprotein aggregates

As mentioned above lipids are not homogeneously dispersed in wheat flour since they depend on the distribution and organisation imposed by the development of the cells and tissues of the grain. These lipid organisations are more or less affected on dehydration on grain development. Especially, important modifications are observed in the case of starchy endosperm where the cell organisation totally disappeared in contrast with that it is observed in aleurone and embryo which have to participate to the renewal of the plant on germination [7-8].

In wheat endosperm of mature dry seeds, membrane lipids form aggregates mainly of the non bilayer types forming long tubules or granular structures characteristic of liquid-crystalline hexagonal II and cubic phases, respectively (figure 2). When water diffuses in the dry endosperm or in wheat flour numerous lamellar vesicles are observed growing from the non lamellar aggregates. In wheat doughs numerous oil droplets are observed which should correspond to the oil bodies (oleoso mes) of the aleurone layer and embryo. At the end of dough mixing or in gluten only oil droplets and lipid vesicles are observed [7-8].These transitions lead to a better dispersion of lipids and especially of polar (membrane) lipids into the dough (figure 2). Observation of such lipid phase transitions from flour to dough and gluten are well predicted from the phase diagram obtained for extracted wheat polar lipids [9]. 
Wheat lipids, oil-water and gas-water interfaces

The texture of baked food products is closely related to the expansion of gas bubbles on proofing and baking stages. Scanning electron microscopy shows that on gas expansion, bubbles can be separated from neighbours only by thin films with an aqueous inter-lamellar phase essentially devoid of the gluten matrix [10]. Before starch gelatinisation and the formation of a solid sponge in bread, these thin films are probably stabilised by adsorbed layers of surface active material. Soluble proteins, i.e. albumins and globulins, and polar lipids are the surface active components of the aqueous phase of dough [11]. The spreading and stability of lipid and lipid-protein films play an important role during the preparation and baking of loaves and sponge cakes.

MacRitchie and co-workers [11] have highlighted a close relationship between the effect of wheat lipids on the bread volume and their effect on the foaming properties of the aqueous phase of dough (figure 3). Non-polar lipids, e.g. triglycerides and free fatty acids which are anti-foaming agents are also detrimental to bread volume. On the contrary above a threshold content, polar lipids improve both the foaming properties of the aqueous phase of dough and bread volume (figure 3 ). The transfer of the lipid vesicles from the bulk water to the air-water or oil-water interfaces is therefore a key mechanism for the expression of lipid functionality [7-8]. This transfer is under the control of lipid-lipid and lipid-protein interactions that determine the foam capacity of lipids and lipoproteins while these interactions determine the stability of the thin films formed at the air-water interfaces. On the contrary adsorption of oil droplets or molten fat crystals and the subsequent spreading of lipid causes thin film rupture by a Marangoni effect [7-8]. Competition for the interface occurs between polar lipids and non lipid binding and soluble proteins. Since proteins form rigid films at the interfaces, the highly mobile polar lipids destabilize the protein films [7-8] (figure 4). This latter mechanism explains likely why, in a defatted flour, adding polar lipids induce first a decrease of bread volume and foam stability of the aqueous phase of dough. In a second step increasing the polar lipid content lead to the formation of thin films stabilized by polar lipids (figure 4).

Wheat lipids oxidation, flavours and dough rheology

The coupled oxidation of cysteine containing storage proteins (free SH groups of gluten proteins) and polyunsaturated fatty acid by lipoxygenases (LOX) induce changes in the rheological properties of doughs and especially improve dough-mixing tolerance [12-13]. These effects increase with increasing work input on mixing and need the presence of the lipid substrates of LOX, monoacylated lipids, e.g. polyunsaturated free fatty acids and monoglycerides. Such lipids are naturally present in wheat flour but can be release from other acylated lipids such as triglycerides, phospholipids and glycolipids under the action of lipases. LOX and lipases are mainly located in the embryo but can be added as soybean or fababean flours. Furthermore the oxidation of polyunsaturated fatty acids leads to complex reactions inducing the formation of smaller molecules (aldehydes, ketones...) with flavouring properties. Finally LOX and other oxido-reducing enzymes are known to produce bleaching of pigments and formation of white crumb [13]. 
From lipid-protein interactions to lipid-binding proteins

Since the significant role of lipids has been highlighted in wheat processing, it has become evident that non covalent interaction with macromolecular components and especially with proteins, should be also important. Besides the competition between lipids and proteins for interfaces and the adsorption-denaturation of most soluble proteins to oil water-interfaces (emulsion) that were evoked above, there are, in all biological matter, proteins that are associated with lipids (membrane proteins, apolipoproteins) or that can spontaneously associate with lipids and lipid aggregates, i.e. lipid binding proteins. Since 1940, many putative lipid binding proteins have been isolated from wheat flour using organic solvents such as hexane and chloroform-methanol [14-15]. In all cases these procedures led to the isolation of low molecular and cysteine-rich proteins including thionins and amylase inhibitors [14-15]. Since 1990, using mild biochemical extraction and fractionation procedures, two main lipid binding proteins families were isolated from wheat flour, lipid transfer proteins and puroindolines [16-17]. Both protein families belong to albumins. Lipid transfer proteins are capable of binding monomeric lipids while puroindolines interact only with lipid aggregates (see below).

Lipid transfer proteins

\section{Structure and interactions with lipids}

Lipid transfer proteins are ubiquitous plant proteins that are capable of enhancing, in vitro, the intermembrane transfer of different types of polar lipids [18-19]. They have been discovered by 1975, in the search of proteins involved in lipid trafficking [19]. Plant LTPs are low molecular mass proteins that display, in their amino acid sequences, a common pattern of eight cysteines forming four disulphide bonds (figure 5). Two main families have been identified, LTP1 and LTP2 with molecular masses of $9 \mathrm{kDa}$ and $7 \mathrm{kDa}$, respectively [18]. LTPs belong to multigenic families whose genes are spatially and temporally regulated in all plants and plant organs [18-19]. More than 30 different putative LTPs can be recovered from the genome of the plant model, Arabidopsis thaliana (figure 5). Both LTP1 and LTP2 are found in cereal seeds and are mainly concentrated in the aleurone layer [18]. At least 10 different $L T P$ genes are expressed during wheat seed development (Gautier, personal communication). When the cysteines are not taken into account, LTP1 and LTP2 display low sequence identities while, within a LTP family, sequence identities are generally above $30 \%$. Most LTPs are cationic proteins although the presence of some anionic proteins have been reported [20-21]. Finally, LTP1 and LTP2 display similar cysteine pairing except a mismatch at the Cys$\mathrm{X}$-Cys motif (figure 5). Therefore the cysteine pattern $\varnothing \subset \varnothing \subset \varnothing \varnothing C \varnothing C X \subset \varnothing C \varnothing \mathrm{C}$ is generally considered as the LTP signature.

Both LTP1s and LTP2s are alpha-helix proteins $[18,22]$. In LTP1, the four helices form a bundle-like shape surrounded in part by a C-terminal polypeptide composed by turns forming a saxophone-like structure (figure 6). The four disulphide bonds link helices and the saxophone-like polypeptide to the helices. An hydrophobic tunnel, forming the lipid binding site (see below) follows the long axis of the 
protein. The rice LTP2 is the only protein of this family for which a structure has been recently determined [22]. LTP2 displays three main helices and two single turn helices (figure 6). Helix H2 and helix $\mathrm{H} 3$ are connected by a $90^{\circ}$ turn that forms a very rigid and unique structural motif. The hydrophobic cavity is a triangular hollow box and not a tunnel. A part of LTP2 and LTP1 structures can be superimposed [22]. The tunnel of LTP1s is highly flexible and its volume increases[MG1] to bind one or two molecules of monoacylated lipids or a diacyl phospholipid [18] (figure 7). Whatever the LTP1 and the lipid, both fluorescence and calorimetry show that the dissociation constant is in the micromolar range [23]. When two monoacylated lipids are bound to the wheat LTP1, the lipids adopt an original head to tail orientation [18] (figure 7). The volume of the hydrophobic cavity of LTP2s is smaller than those of LTP1s but the cavity of LTP2 seems more flexible [22]. Until now no studies have been performed to characterize the interactions of LTP2 with lipids.

At the molecular level, the mechanisms involved in the transfer activity provide some interesting information to understand their technological properties (see below). The transfer activity depends on the capacity of the protein to adsorb at the membrane bilayer inteface and to bind lipid molecules. Concerning adsorption, it has been shown that maize seed LTP1 can penetrate lipid monolayers at higher surface pressure than wheat seed LTP1s [24] in agreement with the higher transfer activity of the maize protein [25]. This is due in part to the surface hydrophobicity of the protein and it has been shown that surface hydrophobization increases transfer activity [26]. The net positive charge and its distribution on the surface of LTPs seem also important for their lipid transfer activity [22] in agreement with an increase of transfer when anionic lipids are present in the membrane bilayers [25].

Technological functions of LTPs

The role of LTPs on the quality of food has been demonstrated only in brewing technology. LTP1 is one of the major proteins of beer (about $50 \%$ of beer proteins) that is involved in both the formation and stability of head foams [27]. LTP1 survive malting and brewing processes because they are highly stable and resistant to proteases [28]. While beer nsLTP1 contributes to the formation of head foam of beer, the barley LTP1 does not display any foaming capacity [27]. Most of the barley LTP1 is glycated through Maillard reactions on malting [29]. The glycated protein is, in part, denaturated during brewing due to both the reduction of disulphide bonds and heating treatment on brewing [3132]. Glycation improves the solubility and amphiphilicity of denaturated beer LTP1 that can adsorb and form aggregated and more stable protein films at air-water interfaces (figure 8).

Looking back at the breadmaking process, LTPs, through their transfer activity, can play a role in the equilibrium between lipids in the aqueous phase of dough and thin films formed at air and oil-water interfaces. Such a phenomenon was highlighted by monolayer studies [33]. Since LTPs are capable of binding free fatty acids, they could prevent destabilization of dough foam by these lipids [34 and above]. As observed in beer, denaturation induced by oxido-reducing agents added in some bread formulations (ascorbic acid for example) can improve the surface properties of LTPs within the 
aqueous phase of dough. Finally, LTPs could play a role on the activity of lipases and LOX that work at the oil-water interfaces (although it cannot be predicted if these enzymes are activated or inhibited by LTPS).

Puroindolines

Structure and interaction with lipids

As LTPs, puroindolines are basic and cysteine-rich proteins. We have given this name to these proteins in regard to the unique tryptophan-rich domain Trp-Arg-Trp-Trp-Lys-Trp-Trp-Lys displayed by the major protein that we have sequenced (indoline, for the indole ring of tryptophan and puros, a greek word for wheat) [17]. Puroindolines are composed by two main isoforms, puroindoline-a (PIN-a) and puroindoline-b (PIN-b). From a cDNA library, Rahman et al. [35] have isolated other puroindoline-like proteins named grain softness proteins (GSP) that have not been yet isolated from wheat kernel. In regard to the major protein (PIN-a), the tryptophan-rich domain is truncated in PINb [Trp-Pro-Thr-Trp-Trp-Lys] the second isoform isolated from wheat flour [18] and in GSPs, most of the tryptophans are replaced by phenylalanine [35] (figure 9). Genes encoding homologous proteins have been found in oat, barley, and rye $[18,36]$. Indolines are not found in rice and maize $[18,36]$ as well as sequencing of the Arabidopsis genome does not reveal the presence of homologous proteins. Indolines are cereal seed specific proteins of the Triticae and Avenae tribes $[18,36]$ contrary to nsLTPs which are ubiquitous in the plant kingdom.

The three dimensional structure of puroindolines has not yet been determined. However, circular dichroism and FTIR data show that these proteins, as LTPs, display a high helix content [18]. Cysteine pairing of puroindolines is identical, for eight cysteines, to that of LTP2 (figure 9). The two extra cysteines that enclosed the tryptophan-rich domain of puroindolines form a disulphide bond [18] (figure 9) so that it is suggested that this tryptophan-rich region could form a loop. These similarities of cysteine pairing and helix content strengthen the fact that LTPs and puroindolines could display similar folds. Other plant alpha-helical proteins that display a similar cysteine motif have an ORTP fold[? such as the hydrophobic protein of soybean [37], the wheat alpha-amylase inhibitor [38] and the $2 \mathrm{~S}$ seed storage proteins [39]. These proteins do not possess an hydrophobic tunnel.

Contrary to nSLTP, puroindolines can only interact with a lipid interface and not with monomeric lipids. Thus, in the case of phospholipids forming micelles, interaction occurs only above the CMC [40]. The stoichiometry is generally 4-5 lipids bound per protein in agreement with their capacity to anchor in lipid aggregates such as micelles and bilayers vesicles [40-41] and with the probable absence of a cavity within the protein. As observed for LTP1, these basic proteins interact more with negatively charged phospholipids than with neutral polar lipids such as phosphatidylcholine or galactosylglycerides [41] (table 1). Furthermore an important difference of the interaction is observed between PIN-a and PIN-b which is probably due to the loss of tryptophan residues in the corresponding domain [41]. However it is interesting to note that PIN-b interacts more strongly with anionic lipids than PIN-a [41]. Since PIN-b displays a higher positive net charge than PIN-a, these 
results suggest that both hydrophobic and electrostatic contribution are essential in the interaction of puroindolines with polar lipids.

Puroindolines and interfaces

Puroindolines are surface active proteins that adsorb spontaneously at air-water interfaces [42-43] and form very stable foams [18]. The stability of puroindoline foams is intrinsically high, for example about ten times higher than the stability of egg white protein foams [40]. However, the most interesting feature of puroindoline foams is their high resistance to destabilisation by lipids. Furthermore, in presence of lipid surfactants, a synergistic enhancement of foam stability of puroindolines is observed [18, 40] (figure 10). Such a phenomenon is unique since surfactants compete with proteins for the air-water interfaces leading to the destabilization of protein foams [44-45]. This synergy is well related to the affinity of puroindolines with lipids and for example this effect is less pronounced for PIN-b which interact less strongly with some polar lipids $[40,41]$.

These unique surface properties of puroindolines are also observed in food and beverages [40, 4647]. In beer as in egg white, it has been shown that slight amounts of puroindolines can restore protein foams destabilised by lipids $[40,46]$. In bread, puroindolines lead to crumb with an homogeneous structure composed of fine gas cells [47] as the fine bubbles observed for puroindoline foams (figure 11). Different experiments suggest that puroindolines prevents the foam destabilisation of the aqueous phase of dough by lipids [48]. Concerning the bread volume, an increase or a decrease can be obtained according to the rheological properties of the wheat flour dough [47]. The dough viscoelasticity can interfere in gas cell growth on mixing, fermentation and baking. This interference is relatively complex since surprinsingly puroindolines induced also significant changes in the rheological properties of wheat flour doughs, e.g. an increase of tenacity and a decrease of extensibility of the dough [47]. Adsorption of puroindolines at water-lipid interfaces could activate enzymes, e.g. lipases and LOX, that works at these interfaces and that are known for their impact on dough rheology $[12,13]$ as it was suggested above for LTPs.

Puroindolines and endosperm texture

The texture of the wheat endosperm, i.e. hardness or softness is generally considered as a physical parameter that determines the end uses of wheats. While hard wheats are well adapted for breadmaking, soft wheats are used for making cookies, biscuits and pastries. The texture of endosperm determine the content in damaged starch and therefore the water retention of doughs. The texture of wheat endosperm is mainly related to the expression of a gene, the hardness Ha gene, located on the short arm of chromosome 5D [49-50]. Greenwell and Schofield [51] highlighted a close relationship between softness and the presence, on the surface of water-washed starch granules, of a protein with an apparent molecular mass of 15,000 Da by SDS-PAGE. This protein fraction that has been named friabilin or grain softness proteins are mainly composed by puroindolines $[18,49-50]$. 
An interesting feature is that generally PIN-a free cultivar are always hard or very hard wheats [18, 49-50]. PIN-a gene is located on the short arm of chromosome 5D at proximity of the $\mathrm{Ha}$ gene [18, 49-50]. Allelic variations of the wild PIN-b gene have been highlighted that lead to single amino acid replacements and are highly associated to hardness [49-50]. These mutations are not systematically observed in hard wheats but, in such a case, preliminary observations suggested that hard wheats are PIN-a null variants [49]. This hypothesis was not confirmed for some Australian hard wheats where both the [soft PIN-b allele? without the null PIN-a allelic variation were highlighted [52].

Considering the whole endosperm, it was shown that puroindoline contents are often similar in most hard and soft wheat although there is a tendency for lower amounts in hard wheat kernels [47]. On a sample of 40 wheat cultivars grown in four different locations, it was shown that the PIN-b content was more related to grain hardness than the PIN-a content and that heritability of hardness and PINb content are similar [53]. It was suggested that the presence of puroindolines on the surface of starch could be lipid mediated [49] in agreement with the strong binding properties of these proteins with wheat lipids and localisation studies performed on mature wheat kernels [18].

Therefore if, at the genetic level, some allelic variations are obviously related to the texture of wheat endosperm, there are no clear relationships at the expression level, i.e. considering puroindoline contents. Furthermore, a recent study demonstrated that the interaction of puroindolines with starch granules isolated from both hard and soft wheats was similar [54]. These contradictory results suggest that puroindolines are not the cause of softness but a consequence of it. In other words, other physicochemical factors are responsible for the presence or absence of puroindolines on the surface of starch. In regard to the strong interactions of puroindolines with lipids and the close association between the ?free lipids? content and $\mathrm{Ha}$ gene [55], these molecules should play a significant role on the texture of endosperm. Finally the role of puroindolines in wheat hardness is far from what we can expect when friabilins and identities between puroindolines and friabilins were discovered. Nevertheless, puroindolines are still the only marker available for further investigations of the $\mathrm{Ha}$ gene.

\section{CONCLUSION}

Today we have a relatively good overall view of the mechanisms that explain the role of lipids and lipid-protein interactions on cereal processing and on the quality of cereal derived food products. Although some of the mechanisms are still hypothetical, we have new opportunities for improving the functionality of lipids through the use of enzymes (e.g. lipases, lipoxygenase) and the control of lipid-protein interactions through specific lipid binding proteins, e.g. LTPs and especially puroindolines. Therefore, to fulfil these objectives, it becomes now essential to consider the corresponding genes in future breeding programmes. With lipid binding proteins and especially with puroindolines, we have for the first time an alternative to the manipulation of the gene of storage proteins (gluten proteins) in the general objective of improving breadmaking quality of wheats. Furthermore LTP and puroindolines are also interesting proteins in agronomy since they are involved 
in the resistance of plants against microbial pathogens $[49,56]$. However, in the case of LTPs, it should be cautious that no allergy risk could be developed since these proteins seems to be panallergens of plant derived foods [57].

\section{REFERENCES}

1 - Morrison WR. Lipids. In: Wheat chemistry and Technology Y. Pomeranz, ed, AACC, St-Paul, Minnesota ; 1988 : vol.1, 373-439.

2 - Kolattukudy PE. Polyesters in higher plants. Adv Biochem Enginee 2001 ; 71 : 1-49.

3 - Matzke K, Riederer M. The composition of the cutin of the caryopses and leaves of Triticum aestivum L. Planta $1990 ; 182$ : 461-6.

4 - Sieber P et al. Transgenic Arabidopsis plants expressing a fungal cutinase show alterations in the structure and properties of the cuticle and postgenital organ fusions. Plant Cell $2000 ; 12: 721-38$.

5 - Tanaka $\mathrm{H}$ et al. A subtilisin-like serine protease is required for epidermal surface formation in Arabidopsis embryos and juvenile plants. Development $2001 ; 128: 4681-9$.

6 - Galliard T. Enzymic degradation of cereal lipids. In: Lipids in Cereal Technology, PJ Barnes, ed, Academic Press, New York ; 1983 : 111-48.

7 - Marion D, Clark DC. Wheat lipids and lipid binding proteins: structure and function, In: Wheat structure, biochemistry and functionality, JD Schofield, ed, Royal Society of Chemistry ; 1996 : 24560.

8 - Marion D, Dubreil L, Wilde PJ, Clark DC. Lipids, lipid-protein interaction and the quality of cereal products. In: Interactions in Cereal Products, K Hoseney, RJ Hamer, eds, AACC, Saint-Paul, Minnesota ; 1998 : 131-67.

9 - Larsson K. Functionality of wheat lipids in relation to gluten gel formation. In: Chemistry and Physics of Baking, JMV Blanshard, JP Frazier, T Galliard, eds, Royal Society of Chemistry, London ; $1986: 62-74$. 
10 - Gan Z, Angold RE, Williams MR, Ellis PR, Vaughan JG, Galliard T (1990). The microstructure and gas retention of bread dough. J. Cereal Sci, 12 : 15-24.

11 - Macritchie F. The role of lipids in baking. In: Lipids in Cereal Technology, PJ Barnes, ed., Academic Press, New York ; 1983 : 165-88.

12 - Frazier PJ. Lipid-protein interactions during dough development. In: Lipids in Cereal Technology, PJ Barnes, ed., Academic Press, New York ; 1983 : 189-212.

13 - Nicolas J, Drapron R. Lipoxygenase and some related enzymes in breadmaking. In: Lipids in Cereal Technology, PJ Barnes, ed, Academic Press, New York ; 1983 : 213-35.

14 - Balls AK, Hale WS. A sulphur bearing constituent of the petroleum ether extract of wheat flour (preliminary report). Cereal Chem $1940 ; 17: 243-5$.

15 - Redman DG, Ewart JAD. Characterisation of three wheat proteins found in chloroform-methanol extract. J Sci Food Agric $1973 ; 24$ : 629-36.

16 - Desormeaux A, Blochet JE, Pezolet M, Marion D. Amino acid sequence of a non-specific wheat phospholipid binding protein and its conformation revealed by infra-red and Raman spectroscopy. Role of disulphide bridges and phospholipids in stabilizing the alpha-helix. Biochim Biophys Acta 1992 ; 1121 : 137-52.

17 - Blochet JE et al. Complete amino acid sequence of puroindoline, a new basic and cystine-rich protein with a unique tryptophan-rich domain, isolated from wheat endosperm by Triton X114 phase partitioning. FEBS Lett $1993 ; 329: 336-40$.

18 - Douliez JP, Michon T, Elmorjani K, Marion D. Mini Review: Structure, biological and technological functions of lipid transfer proteins and indolines, the major lipid binding proteins from cereal kernels. J Cereal Sci $2000 ; 32: 1-20$.

19 - Kader JC. Lipid transfer proteins in plants. Ann Rev Plant Physiol Plant Molec Biol 1996 ; 47 : 627 54.

20 - Blanckaert A, Belingheri L, Sautiere PE, Vasseur J, Hilbert JL. 9-kDa acidic and basic nsLTP-like proteins are secreted in the culture-medium conditioned by somatic embryogenesis in Cichorium. Plant Physiol Biochem $2002 ; 40$ : 339-45. 
21 - Arondel V, Vergnolle C, Cantrel C, Kader JC. Lipid transfer proteins are encoded by a small multigene family in Arabidopsis thaliana. Plant Sci $2000 ; 157: 1$-12.

22 - Samuel D, Liu YJ, Cheng CS, Lyu PC. Solution structure of plant nonspecific lipid transfer protein2 from rice (Oryza sativa). J Biol Chem $2002 ; 277$ : 35267-73.

23 - Douliez JP, Jegou S, Pato C, Molle D, Tran V, Marion D. Binding of two mono-acylated lipid monomers by the barley lipid transfer protein, LTP1, as viewed by fluorescence, isothermal titration calorimetry and molecular modelling. Eur J Biochem $2001 ; 268$ : 384-8.

24 - Subirade M, Marion D, Pezolet M. Interaction of two lipid binding proteins with membrane lipids: comparative study using the monolayer technique and IR spectroscopy. Thin Solid Films 1996 ; 284/85 : 326-9.

25 - Petit MC, Sodano P, Marion D, Ptak M. Two-dimensional 1H-NMR studies of maize lipid transfer protein -sequence specific assignment and secondary structure. Eur J Biochem $1994 ; 222$ : 1047-54.

26 - Pato C, Tran V, Marion D, Douliez JP. Effects of acylation on the structure, lipid binding, and transfer activity of wheat lipid transfer protein. J Protein Chem $2002 ; 21$ : 195-201.

27 - Sorensen SB, Bech LM, Muldbjerg TB, Breddam K. Barley lipid transfer protein 1 is involved in beer foam formation, MBAA Technical Quater 1993 ; 30 : 136-45.

28 - Lindorff-Larsen K, Winther JR. Surprisingly high stability of barley lipid transfer protein, LTP1, towards denaturant, heat and proteases. FEBS Lett $2001 ; 488: 145-8$.

29 - Jegou S, Douliez JP, Molle D, Boivin P, Marion D. Evidence of the glycation and denaturation of LTP1 during the malting and brewing process. J Agric Food Chem $2001 ; 49$ : 4942-9.

30 - Bech LM, Vaag, P, Heinemann B, Breddam K. Throughout the brewing process barley lipid transfer protein1 (LTP1) is transformed into a more foam-promoting form. Proc Eur. Brew Conv $1995 ; 22: 561-8$.

31 - Marion D, Jegou S, Douliez JP, Gaborit T, Boivin P. Generation of foaming proteins along the malting and brewing processes. Proc Eur Brew Conv $2001 ; 28$ : 631-8. 
32 - Jegou S, Douliez JP, Molle D, Boivin P, Marion D. Purification and structural characterization of LTP1 polypeptides from beer, J Agric Food Chem $2000 ; 48$ : 5023-9.

33 - Subirade M, Salesse C, Marion D, Pezolet M. Interaction of a non specific wheat lipid transfer protein with phospholipid monolayers imaged by fluorescence microscopy and studied by infrared spectroscopy. Biophys J $1995 ; 69$ : 974-8.

34 - Cooper DJ, Husband FA, Mills ENC, Wilde PJ. Role of beer lipid-binding proteins in preventing lipid destabilization of foam. J Agric Food Chem 2002 ; in press.

35 - Rahman S, Jolly CJ, Skerritt JH, Wallosheck A. Cloning of a wheat 15-kDa grain softness protein (GSP). GSP is a mixture of puroindoline-like polypeptides. Eur J Biochem $1994 ; 223$ : 917-25.

36 - Gautier MF, Cosson P, Guirao A, Alary R, Joudrier P. Puroindoline genes are highly conserved in diploid ancestor wheats and related species but absent in tetraploid Triticum species. Plant Sci 2000 ; 153, 81-91.

37 - Baud F, Pebay-Peyroula E, Cohen-Addad C, Odani S, Lehmann MS. Crystal structure of hydrophobic protein from soybean: a member of a new cysteine-rich family. J Mol Biol 1993 ; 231 : 877-87.

38 - Oda Y, Matsunaga T, Fukuyama K, Miyazaki T, Morimoto T. Tertiary and quaternary structures of 0.19 alpha-amylase inhibitor from wheat kernel determined by X-ray analysis at 2.06 a resolution. Biochemistry 1997 ; 36 : 13503-11.

39 - Rico M, Bruix M, Gonzales C, Monsalve RI, Rodriguez R. 1H NMR Assignment and global fold of napin Bnlb, a representative 2 S albumin seed protein. Biochemistry $1996 ; 35: 15672-82$.

40 - Husband F, Wilde PJ, Marion D, Clark DC. A comparison of the foaming and interfacial properties of two related lipid binding proteins from wheat in the presence of a competiting surfactant. In: Food Macromolecules and Colloids, E Dickinson, D Lorient, eds, Royal Society of Chemistry, London ; 1994 : 285-96.

41 - Dubreil L, Compoint JP, Marion D. The interaction of puroindolines with wheat polar lipids determines their foaming properties. J Agric Food Chem $1997 ; 45$ : 108-16.

42 - Biswas SC, Dubreil L, Marion D. Interfacial behaviour of wheat puroindolines monolayers of puroindolines at the air-water interface. Colloid Polym Sci $2001 ; 279$ : 607-14. 
43 - Biswas SC, Dubreil L, Marion D. Interfacial behavior of wheat puroindolines: study of adsorption at the air-water interface from surface tension measurement using Wilhelmy plate method. J Colloid Interface Sci $2001 ; 244: 245-53$.

44 - Chen J, Dickinson E, Iveson G. Interfacial interactions, competitive adsorption and emulsion stability. Food Structure $1993 ; 12: 135-46$.

45 - Wilde PJ, Clark DC. Competitive displacement of beta-lactoglobulin by Tween 20 from oil-water and air-water interfaces. J Colloid Interf Sci $1993 ; 155$ : 48-54.

46 - Clark DC, Wilde PJ, Marion D. The effect of lipid binding protein on the foaming properties of beer containing lipid. J Inst Brew 1994 ; 100 : 23-5.

47 - Dubreil L et al. Effect of puroindolines on breadmaking properties of wheat flour. Cereal Chem $1998 ; 5: 222-9$.

48 - Dubreil L, Biswas SC, Marion D. Localization of puroindoline-a and lipids in bread dough using confocal scanning laser microscopy. J Agric Food Chem $2002 ; 50:$ 6078-85.

49 - Morris FC. Puroindolines: the molecular genetic basis of wheat grain hardness. Plant Mol Biol $2002 ; 48: 633-47$.

50 - Turnbull KM, Rahman S Endosperm texture in wheat. J Cereal Sci $2002 ; 36: 327-37$.

51 - Greenwell P, Schofield JD. A starch granule protein associated with endosperm softness in wheat. Cereal Chem $1986 ; 63: 379-80$.

52 - Turnbull KM, Gaborit T, Marion D, Rahman S. Variation in puroindoline polypeptides in Australian wheat cultivars in relation to grain hardness. Aust J Plant Physiol $2000 ; 27$ : 153-8.

53 - Igrejas G, Gaborit T, Oury FX, Chiron H, Marion D, Branlard G. Genetic and environmental effects on puroindoline-a and puroindoline-b content and their relationship to technological properties in French bread wheats. J Cereal Sci $2001 ; 34$ : 37-47. 
54 - Bloch HA, Darlington HF, Shewry PR. In vitro binding of puroindolines to wheat starch granules. Cereal Chem $2001 ; 78: 74-8$.

55 - Morrison WR, Law CN, Wylie LJ, Coventry AM, Seekings J. The effect of group 5 chromosomes on the free polar lipids and breadmaking quality of wheat. J Cereal Sci $1989 ; 9: 41-51$.

56 - Blein JP, Couthos-Thevenot P, Marion D, Ponchet M. From elicitins to lipid-transfer proteins: a new insight in cell signalling involved in plant defence mechanisms. Trends Plant Sci $2002 ; 7$ : 293-6.

57 - Marion D, Douliez JP, Gautier MF, Elmorjani K. Plant lipid transfer proteins: relationships between allergenicity and structural, biological and technological properties. In Plant food allergens, PW Shewry, eds, Blackwell Publishing, in press, 2002. 


\section{Illustrations}

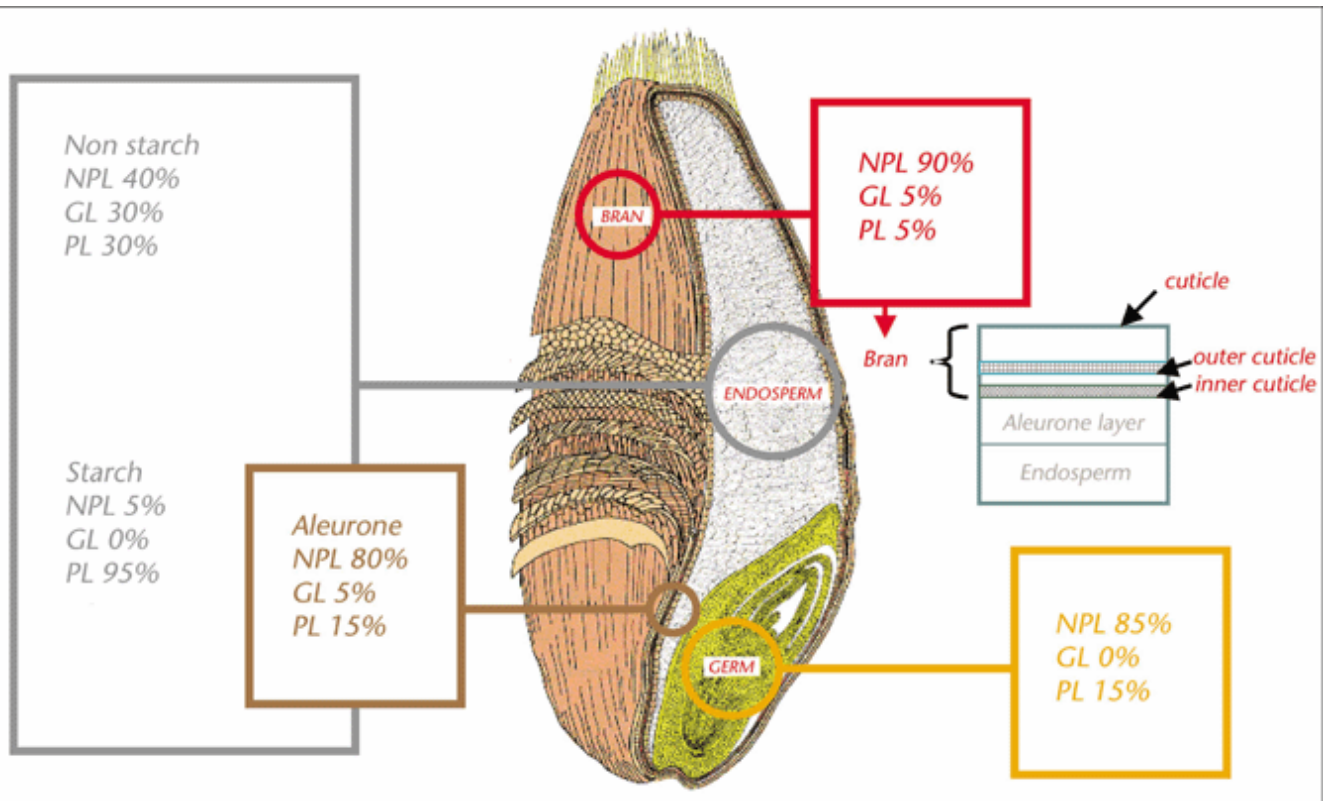

Figure 1 - Composition and distribution of lipids in wheat kernel. Non polar lipids (NPL); glycolipids (GL); phospholipids (PL). The localisation of cuticle layers (cutin + waxes) from bran to starchy endosperm are presented. These hydrophobic layers are also present between embryo and endosperm.

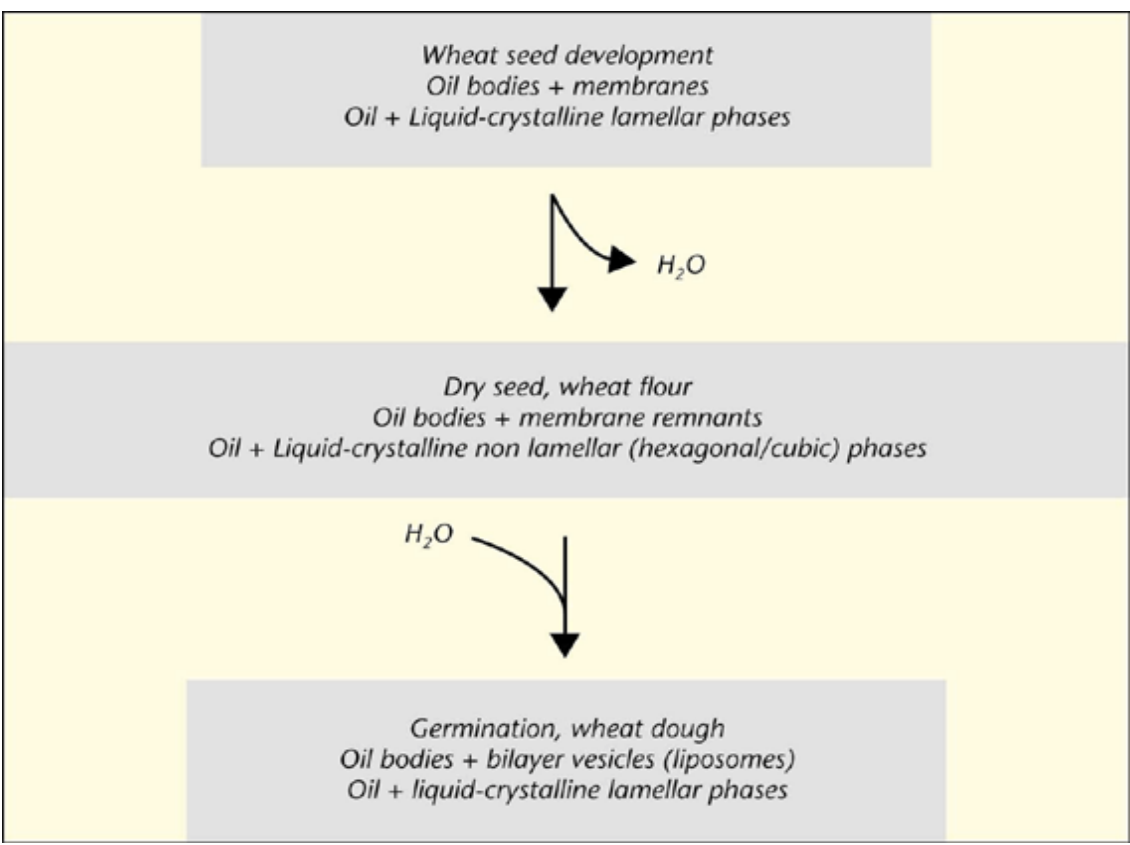

Figure 2 - Liquid-crystalline rearrangements of lipids from seed to dough. 


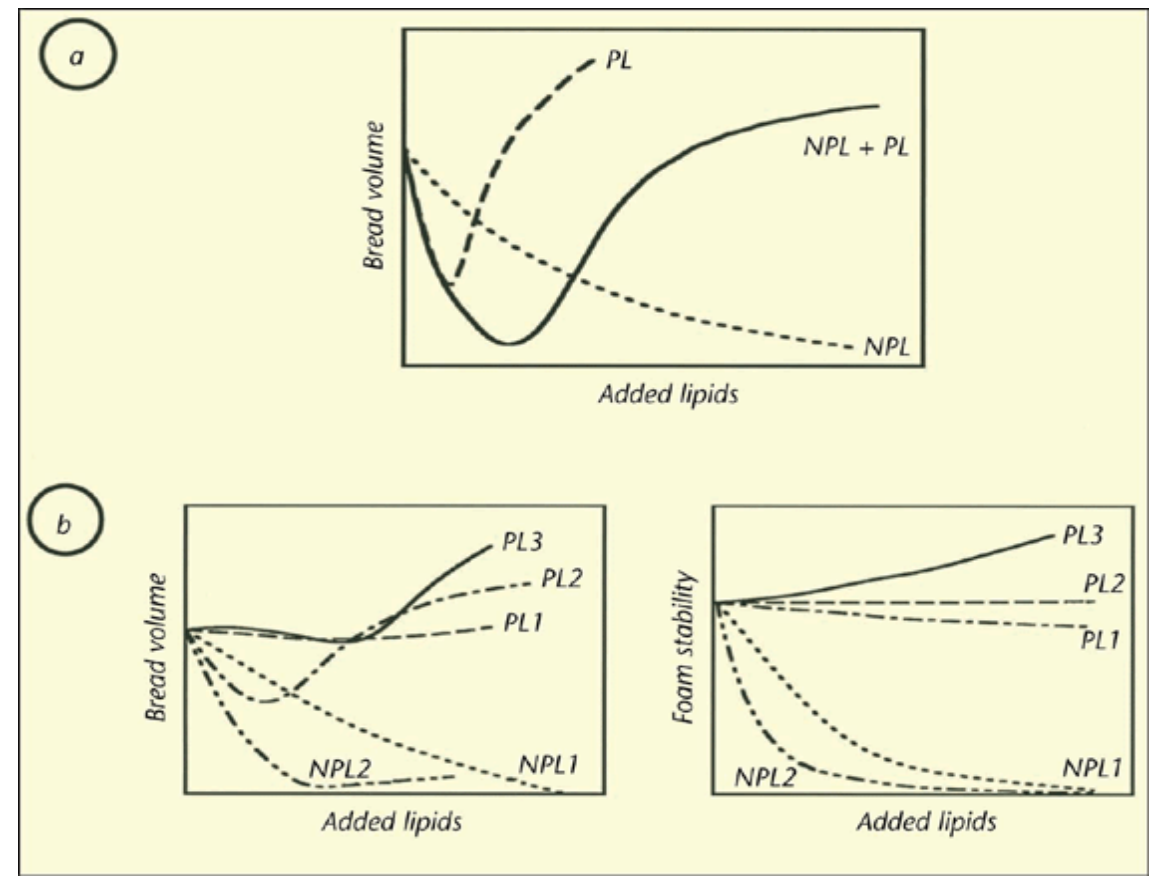

Figure 3 - Effect of lipids on bread volume and on the foaming properties of the aqueous phase of dough. (a) Effect of extracted total lipids (NPL $+P L$ ), non polar lipids (NPL) and polar lipids (PL) on the volume of a bread obtained from a chloroformdefatted wheat flour. (b) Effect of different non polar lipid (NPL1, NPL2) and polar lipid fractions (PL1, PL2, PL3) on the bread volume (left) and foaming stability of the aqueous phase (right) of a defatted wheat flour (adapted from MacRitchie [11]).

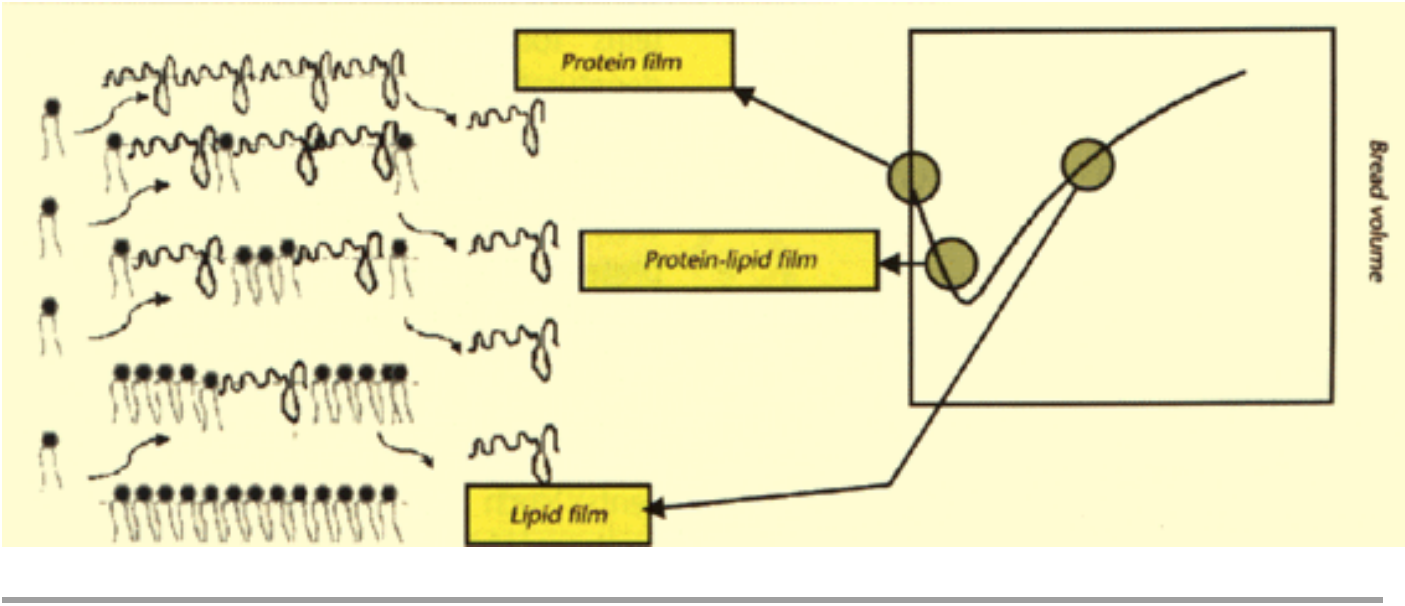

Figure 4 - Schematic representation of the competition between polar lipids and soluble proteins of the aqueous phase of dough for the air-water interfaces (left) and possible relationships with the effect of polar lipids on bread volume (right). 


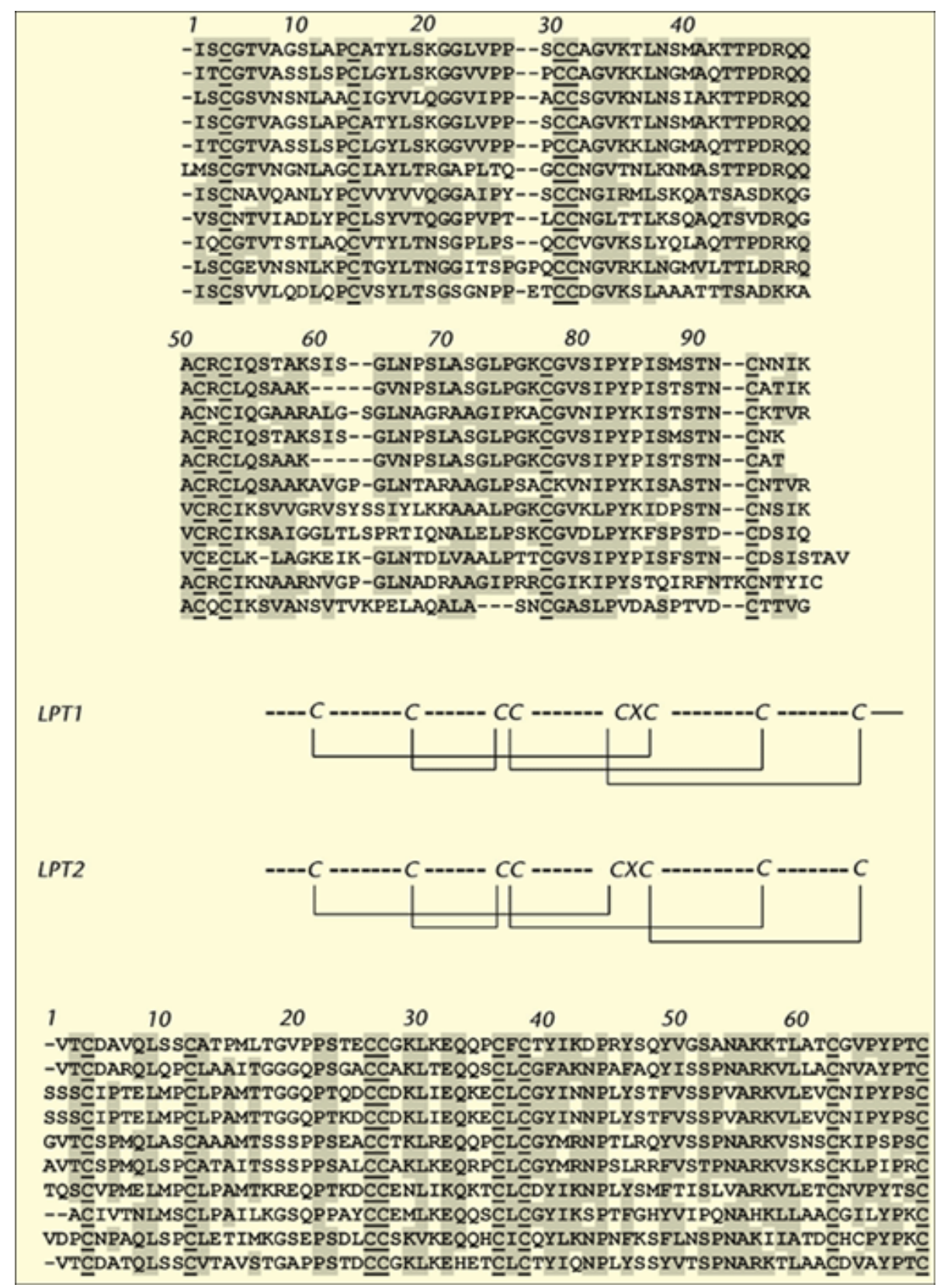

Figure 5 - Amino acid sequences of different putative LTP1s and LTP2s from the Arabidopsis genome (BLAST at http: \www; arabidopsis.org) with the corresponding cysteine pairing of LTP1 and LTP2s. 

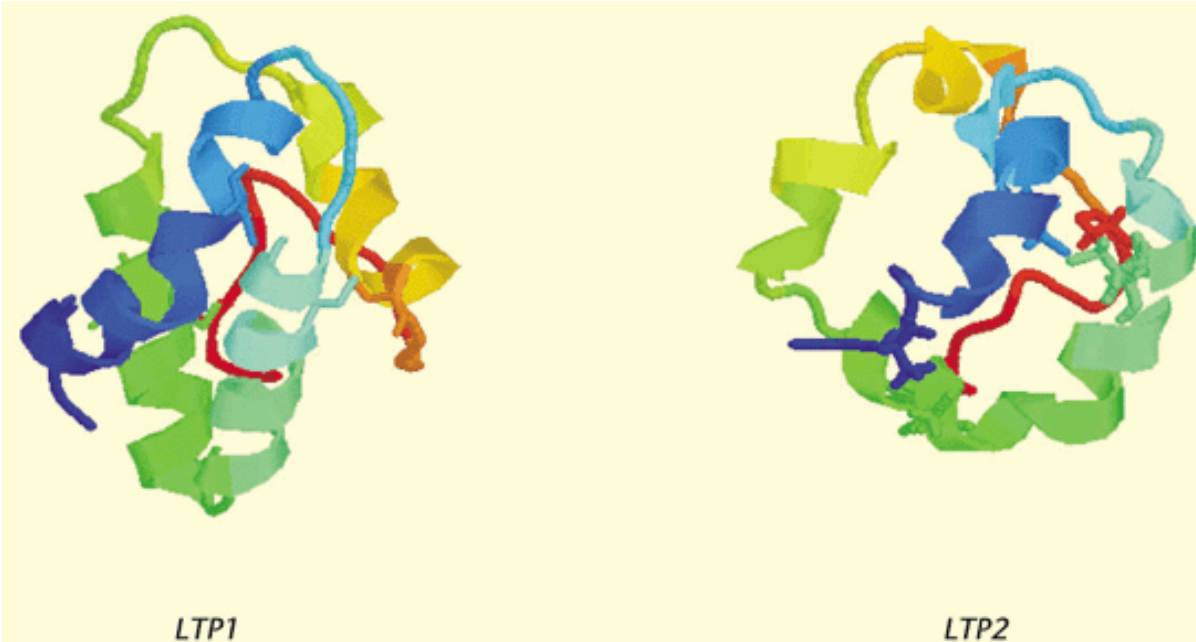

LTP1

Figure 6 - Structural characteristic of LTP1 and LTP2.

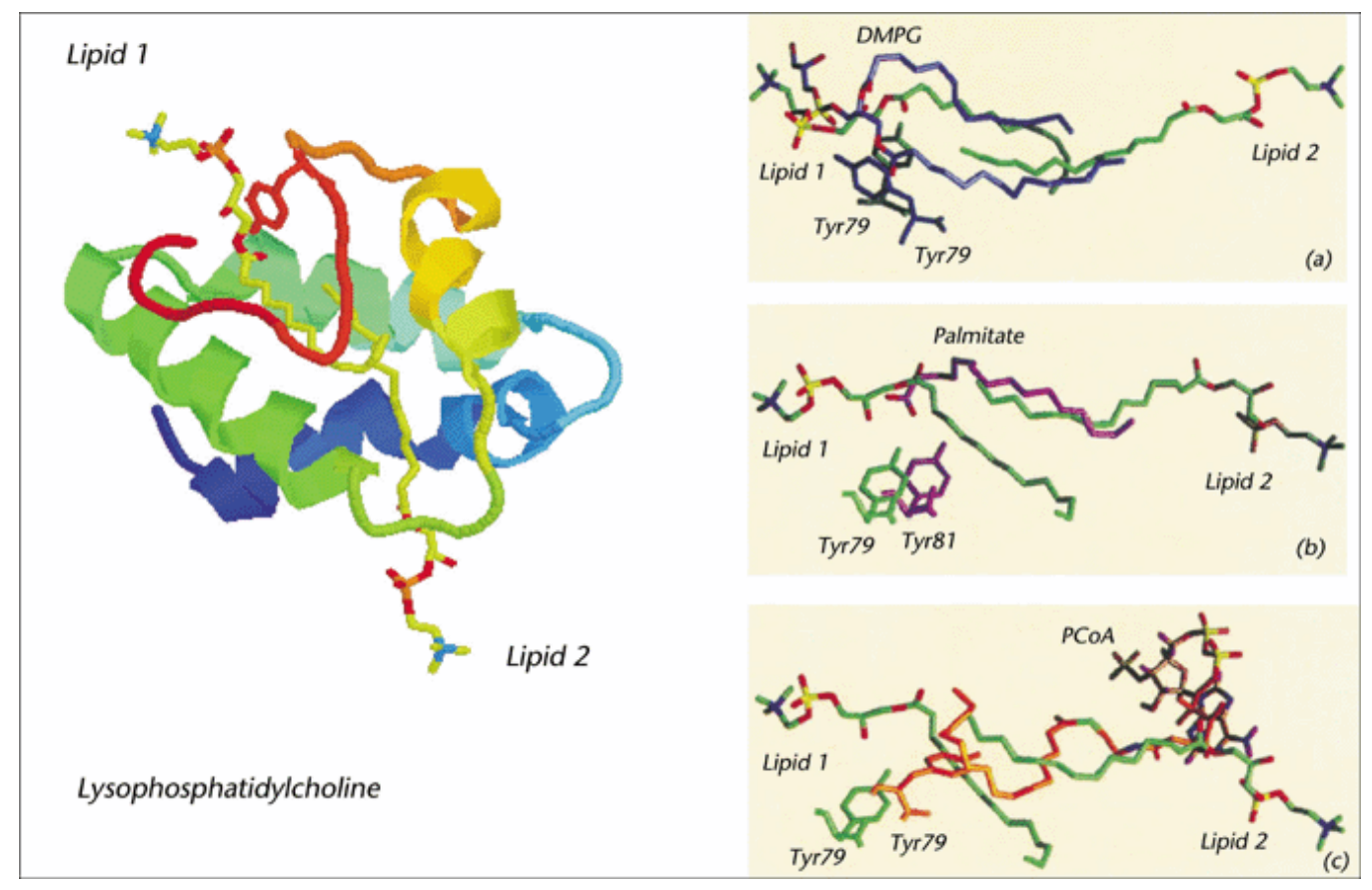

Figure 7 - Structure of different lipid-LTP1 complexes. The structure of wheat LTP1 complexed with two molecules of lysophosphatidylcholine in an head to tail orientation (left). These lipid orientations are compared (right) with those of (a) an anionic phospholipid, dimyristoylphosphatidylglycerol (DMPG) complexed by wheat LTP1, (b) of a fatty acid (palmitate) complexed by maize LTP1 and of an acylcoenzymeA, palmitateCoA (PCoA) complexed by barley LTP1. Tyr 79 (wheat, barley) and Tyr81 (maize) that interact with the lipids (orientation 1) are presented. Adapted from Charvolin et al. [cited in 18]. 


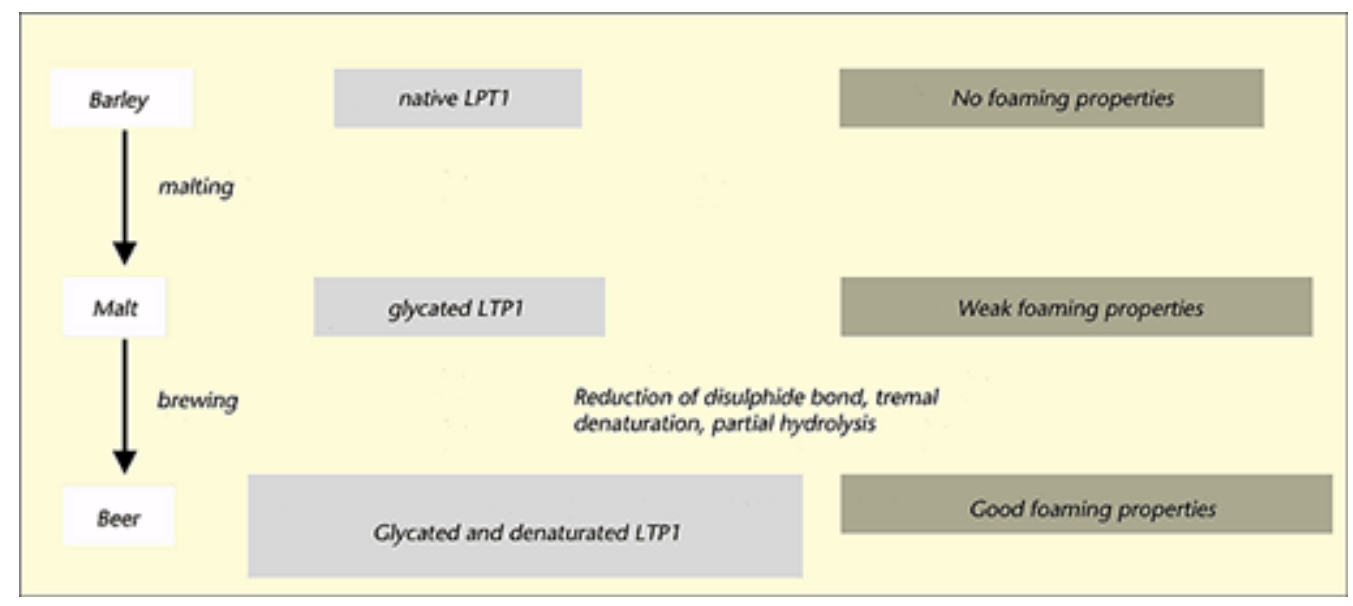

Figure 8 - Physico-chemical and structural modifications of LTPs on malting and brewing.

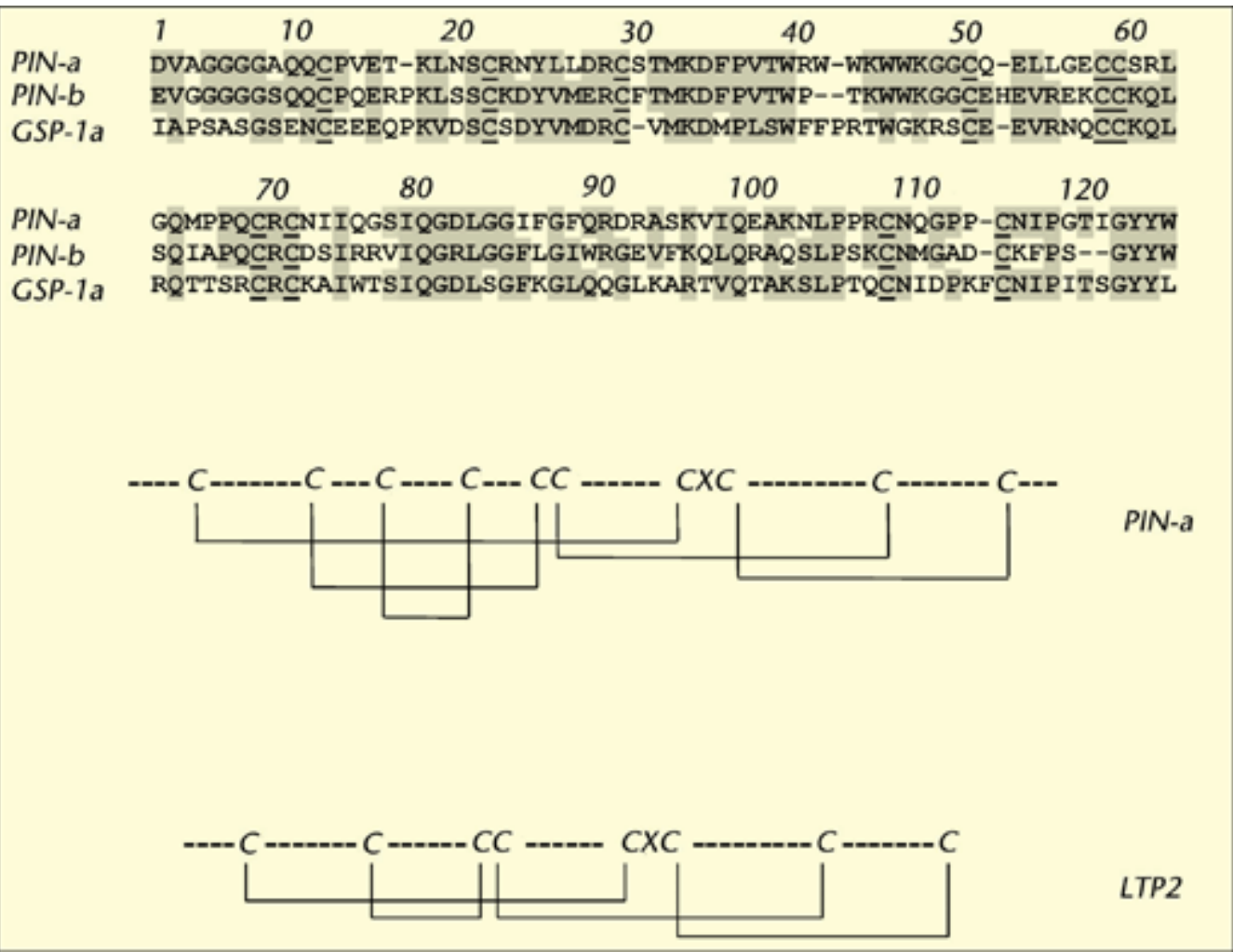

Figure 9 - Amino acid sequence and cysteine pairing of puroindolines, puroindoline-a (PIN-a), puroindoline-b (PIN-b) and a grain softness protein (GSP1a). 


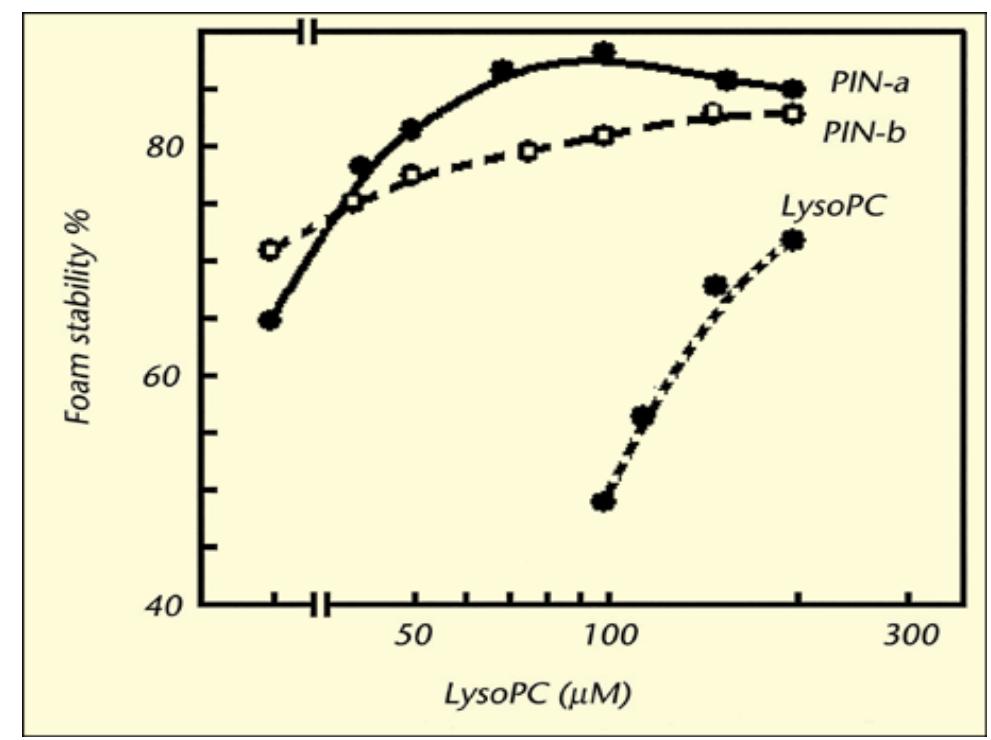

Figure 10 - Synergistic enhancement of the foaming properties of puroindolines in presence of a model surfactant, lysophosphatidylcholine (lysoPC). From Husband et al. [40].

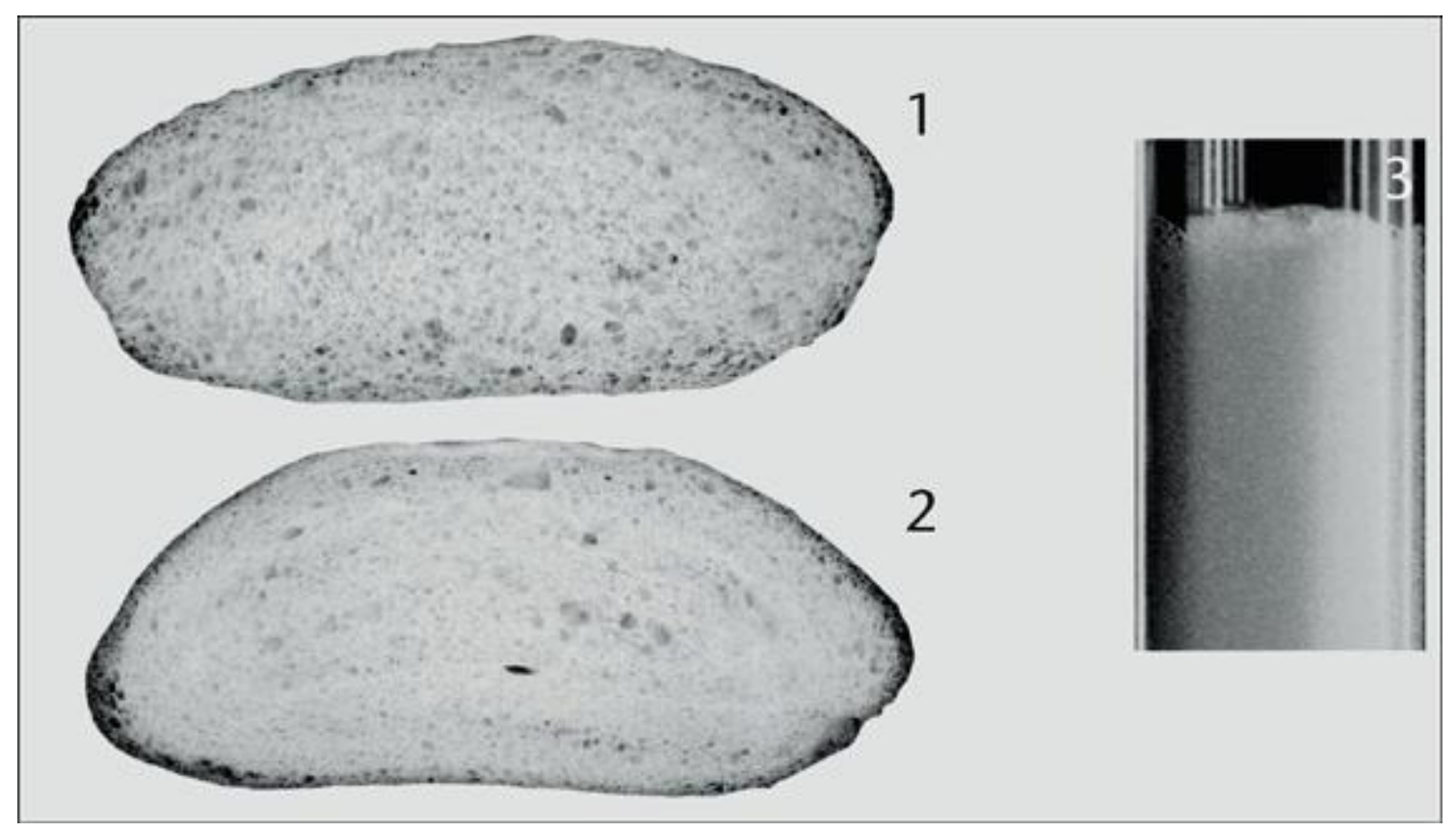

Figure 11 - Effect of puroindolines on the structure of bread crumb (left); standard bread obtained from a PIN-a free cultivar (1) to which $0.1 \%$ puroindoline was added (2). Relationship with the structure of a puroindoline foam (3, right). From Dubreil et al. [48]. 


\begin{tabular}{|lcccc}
\hline & \multicolumn{2}{c}{ PIN-a } & \multicolumn{3}{c}{ PIN-b } \\
\hline & Kd & $n$ & Kd & $n$ \\
& $(\mu \mathrm{M})$ & & $(\mu \mathrm{M})$ & \\
Phospholipids (PL) & 0.14 & 4.1 & 0.04 & 16.3 \\
Glycolipids (CL) & 18.2 & nd & 104.7 & n.d. \\
Total polar lipids & 0.16 & 4.5 & 89 & n.d. \\
$(\mathrm{GL}+\mathrm{PL})$ & & & & \\
\hline
\end{tabular}

Table 1 - Thermodynamic parameters of the interaction of puroindolines with wheat polar lipids.

$\mathrm{Kd}=$ dissociation constant; $\mathrm{n}$ = stoichiometry. 